\title{
Analisis Framing Pemberitaan LGBT pada Website Media SEJUK Edisi Januari 2019
}

\author{
Valentika, Septia Winduwati \\ valentika10@gmail.com, septiaw@fikom.untar.ac.id \\ Fakultas Ilmu Komunikasi Universitas Tarumanagara
}

\begin{abstract}
This study discusses the framing analysis of the January 2019 edition of LGBT issues on SEJUK media. LGBT is still a taboo among the Indonesian people. This study uses a qualitative methodology, the research strategy is framing analysis, which objects and subjects come from COOL media articles, also from interview data. In the selected article there were pros and cons between the media and the church in accepting the LGBT community. By using the concept of Robert N. Entman's framing analysis to be able to see how the SINO media framed the news. The results of this study are broadly outlined, in framing the media SEJUK wants to provide a balanced space to make the public hear alternative voices from those who are intolerant and respectful.
\end{abstract}

Keywords: Mass Communication, Alternative Media, Construction of Media Reality, Framing Analysis, Qualitative Methodology, SINCLE media, LGBT, Robert N. Entman

\begin{abstract}
Abstrak
Penelitian ini meneliti mengenai analisis framing pemberitaan isu-isu LGBT edisi bulan Januari 2019 pada media SEJUK. LGBT memang masih menjadi hal tabu di kalangan masyarakat Indonesia. Penelitian ini menggunakan metodologi kualitatif deksriptif, strategi penelitian analisis framing, objek dan subjeknya berasal dari artikel media SEJUK, dan wawancara. Dalam artikel yang dipilih terdapat pro dan kontra antara media sampai pada gereja dalam menerima komunitas LGBT. Dengan menggunakan konsep analisis framing Robert N. Entman untuk dapat terlihat bagaimana media SEJUK membingkai pemberitaan tersebut. Hasil penelitian ini adalah secara garis besar, dalam pembingkaiannya media SEJUK ingin memberikan ruang yang berimbang untuk membuat publik mendengar suara alternatif dari yang tidak toleran dan menghargai.
\end{abstract}

Kata Kunci : Komunikasi Massa, Media Alternatif, Konstruksi Realitas Media, Analisis Framing, Metodologi Kualitatif, media SEJUK, LGBT, Robert N. Entman

\section{Pendahuluan}

Media adalah seperangkat alat atau sarana yang digunakan untuk menyampaikan atau menyalurkan baik pesan maupun informasi dari komunikator kepada khalayak (Cangara, 2006:119). Sementara pengertian media menurut Tamburaka (2012:9) merupakan alat yang digunakan untuk memindahkan pesan dari sumber kepada penerima.

Media massa pada saat ini sudah mencapai bentuk baru, yaitu media online. Penyebaran informasi dalam media ini lebih cepat dan lebih mudah untuk diakses, serta dapat diakses dimana saja asal dengan memiliki fasilitas internet. Hal ini berbeda dengan akses media cetak dan media televisi. 
Indonesia juga merupakan negara yang beragam. Keberagaman tersebut memunculkan pro dan kontra. Isu-isu keberagaman yang marak pada saat ini adalah mengenai kepercayaan atau agama masing-masing masyarakat. Bukan hanya itu, ada pula keberagaman lain seperti LGBT, penyandang disabilitas, maupun mengenai isu perempuan.

Pada media online, tidak sedikit yang menulis konten mengenai keberagaman tersebut. Dari beberapa media online, penulis memilih media Serikat Jurnalis untuk Keberagaman (SEJUK). Serikat Jurnalis untuk Keberagaman adalah sebuah ruang bersama yang diciptakan selepas pertemuan tersebut guna terus mendukung terbentuknya masyarakat, dengan dukungan media massa yang menghormati, melindungi dan mempertahankan keberagaman sebagai bagian pembelaan atas hak asasi manusia.

SEJUK merupakan media dengan background mendukung keberagaman, baik itu mengenai Agama, LGBT, Penyandang Disabilitas, dan juga Perempuan. Berita yang ditampilkan pada portal berita online tersebut berupa topik - topik mengenai keberagaman tersebut, hal tersebut tentu masuk ke dalam kesensitivan berbagai kaum masyarakat (Sumber: SEJUK).

Pemberitaan media dipengaruhi oleh ideologi media sehingga menimbulkan perbedaan dalam produksi berita yang ditampilkan ke masyarakat. Disiplin Ilmu Komunikasi mempelajari tidak hanya sekedar menjadi penikmat berita, namun memandang secara kritis bahwa setiap media memiliki framing dalam membuat berita. Framing digunakan untuk mengetahui bagaimana cara pandang yang digunakan wartawan atau media massa ketika menyeleksi isu dan menulis berita.

Melalui berita, masyarakat mengetahui apa saja yang terjadi berbagai keberagaman di seluruh Indonesia, tetapi yang masyarakat tersebut lihat, ketahui, dan rasakan, tergantung pada jendela yang digunakan. Pandangan lewat jendela, tergantung pada apakah jendela yang dipakai besar atau kecil. Jendela yang lebih besar dapat melihat lebih luas, sementara jendela yang kecil membatasi pandangan masingmasing masyarakat. Dalam berita, jendela itu yang disebut sebagai frame atau bingkai (Eriyanto 2002:219). Frame Robert N. Entman meletakkan dasar - dasar analisis framing serta menempatkan tahapan moral (moral evaluation) dalam analisisnya memudahkan untuk mengetahui sekaligus mengungkap moral apa yang terkandung. Mengenai peristiwa tersebut, menarik untuk melihat lebih jauh framing berita terhadap kasus keberagaman dalam artikel SEJUK.

Rumusan masalah dalam penelitian ini adalah bagaimana media SEJUK membingkai pemberitaan artikel di website mengenai LGBT edisi bulan Januari 2019. Tujuannya untuk mengetahui framing dari media website SEJUK terhadap artikelartikel yang dipublikasikan mengenai komunitas LGBT dalam bulan Januari tersebut.

\section{Metode Penelitian}

Metode penelitian yang digunakan oleh penulis adalah menggunakan analisis framing Robert N. Entman. Konsep framing oleh Robert N. Entman, digunakan untuk menggambarkn proses seleksi dan menonjolkan aspek tertentu dari realitas oleh media. Framing dapat dipandang sebagai penempatan informasi-informasi dalam konteks yang khas sehingga isu tertentu mendapatkan aloksi lebih besar daripada isu yang lain (Eriyanto, 2002:220). 
Dalam konsepsi Entman, framing pada dasarnya merujuk pada pemberian definisi, penjelasan, evaluasi, dan rekomendasi dalam suatu wacana untuk menekankan kerangka berpikir tertentu terhadap peristiwa yang diwacanakan (Eriyanto, 2011 : 222). Analisis framing yang digunakan dalam penelitian ini adalajh analisis framing model Robert N. Entman.

Strategi penelitian yang digunakan oleh penulis adalah analisis framing. Konsep framing telah digunakan secara luas dalam literatur ilmu komunikasi untuk menggambarkan proses penyeleksian dan penyorotan aspek-aspek khusus sebuah realita oleh media. Dalam ranah studi komunikasi, analisis framing mewakili tradisi yang mengedepankan pendekatan atau perspektif multidisipliner untuk menganalisis fenomena atau aktivitas tkomunikasi. Analisis framing digunakan untuk membedah cara-cara atau ideologi media saat mengkonstruksikan fakta. Analisis ini mencermati strategi seleksi, penonjolam dan tautan fakta ke dalam berita agar lebih bermakna, lebih menarik, lebih berarti atau lebih diingat untuk menggiring interpretasi khalayak sesuai perspektifnya (Sobur, 2006 : 162).

\section{Hasil Temuan dan Diskusi}

\section{Artikel Menggereja Bersama LGBT}

LGBT memang masih tabu untuk diperbincangkan di kalangan, termasuk dalam kalangan gereja. Mereka masih dinilai seperti kelompok yang diminoritaskan bahkan di dalam tempat beribadah. SEJUK tampak menyeleksi isu LGBT bahwa seorang LGBT yang beribadah di gereja, diperkenankan tetapi tidak dapat melebihi dari batas jemaat. Khotbah dari salah satu pendeta Persatuan Gereja Indonesia (PGI) adalah Stephen Suleeman, MA, yang memilih Kitab Mikha sebagai ikhtiar agar gereja bisa menerima dan ikut bergumul dalam berbagai tantangan kemanusiaan yang dihadapi LGBT. Dengan pengutipan artikel dari Kitab Mikha dan khotbah yang disampaikan oleh pendeta Stephen menjadi sebuah cara untuk dapat membuat jemaat belajar menerima komunitas LGBT.

Artikel ini menunjukkan bahwa komunitas LGBT tersebut layak mendapatkan peradaban manusia, mereka memerlukan hak-hak yang sama seperti manusia dengan heteroseksual lainnya. Dari Kitab Mikha, SEJUK berusaha untuk menyadarkan para jemaat gereja yang masih menggunjingkan komunitas LGBT yang beribadah.

\section{Artikel Ihwal LGBT, Tempo Melawan Diskriminasi}

Banyaknya media hanya membangun stigma yang cenderung tidak berpihak pada LGBT. Media menganggap bahwa LGBT sangat berdosa. Dalam hal ini, media tidak hanya cukup bersikap netral namun media mampu untuk mengedukasi publik dari pemberitaan LGBT tersebut. Media perlu mengedukasi publik dari prosedur pemberitaannya. Media Tempo bersama dengan media advokasi lainnya seperti GWL Ina, Arus Pelangi memberikan ruang bagi komunitas LGBT membela komunitas dari cara pemberitaannya. Media-media mengenai kasus LGBT selama ini di mana memojokkan serta menyalahkan komunitas tersebut.

\section{Artikel Dalam Meliput LGBT, Kemana Jurnalis Harus Berpihak?}

Media SEJUK melihatkan sisi keberpihakan terhadap LGBT sebagai kelompok yang diminoritaskan oleh media. Media dianggap lalai dalam 
menyuguhkan pemberitaan tentang isu gender seksualitas LGBT karena tanpa mengikuti prosedur-prosedur yang seharusnya. Media mementingkan bisnisnya sendiri tanpa memberikan fakta-fakta ilmiah yang perlu diketahui pula oleh masyarakat. Manager Program SEJUK, Tantowi Anwari menyatakan bahwa banyaknya media yang lebih mengejar bisnisnya dengan mengundang pengiklan dan mengeduakan persoalan keberpihakan tersebut. Media SEJUK membuat kegiatan semacam workshop untuk mempertemukan antara komunitas LGBT dengan kalangan media agar dapat mengembangkan jurnalisme yang mengedukasi publik dan tetap melindungi hak-hak warga negara termasuk komunitas LGBT

Berdasarkan konsep analisis framing yang dilakukan dengan menggunakan model Robert N. Entman yaitu, (Define Problems, Diagnose Causes, Make Moral Judgement, Treatment Recommendation) terhadap pemberitaan artikel yang membahas tentang LGBT dilakukan oleh SEJUK pada edisi bulan Januari 2019.

Pendefinisian masalah (define problems) dari tiga artikel yang ditampilkan seluruhnya menyatakan pembelaan terhadap komunitas LGBT yang didiskriminasi dalam gereja dan juga oleh kalangan media pada pemberitaannya.

Kemudian bagian memperkirakan masalah (diagnose causes), SEJUK menonjolkan bahwa penyebab dari permasalahan ini berasal dari gereja dan media itu sendiri yang belum dapat menerima dan terbuka terhadap komunitas LGBT. Pemilihan narasumber artikelnya merupakan dari pihak yang juga membela komunitas LGBT dari terdiskriminasinya oleh pihak lain.

Dalam membuat keputusan moral (make moral judgement) pada ketiga artikel tersebut SEJUK tampak membandingkan perlakuan negara lain terhadap komunitas LGBT dan beranggapan bahwa media tidak menggunakan prosedur yang semestinya dilakukan oleh seorang jurnalis dalam membuat pemberitaan mengenai LGBT.

Penekanan penyelesaian (treatment recommendation) untuk mengatasi masalah tersebut lebih ke arah mengajak baik kepada jemaat gereja untuk belajar terbuka dan menerima komunitas LGBT yang datang beribadah ke gereja dan juga mengajak komunitas LGBT bertemu langsung dengan kalangan media dalam kegiatan acara workshop yang diselenggarakan oleh SEJUK untuk dapat saling sharing mengenai hal-hal apa yang perlu dikoreksi, diperbaiki serta memberikan ruang kepada LGBT untuk berpendapat demi mencapai sebuah jurnalisme yang dapat mengedukasi publik.

Berdasarkan konsep di atas, secara langsung isi dari pemberitaan tersebut membela dan mendukung hak-hak komunitas LGBT dikarenakan media SEJUK merupakan media alternatif yang membantu menyuarakan hak-hak dari kelompok yang terdiskriminasi oleh pihak-pihak lain. Media alternatif merupakan media yang berorientasi pada masyarakat dan ikut bermain dalam membangun wacana di public sphere. Media ini diharapkan dapat melayani kelompok yang sesungguhnya mayoritas termarjinalisasi. Hubungan teori media alternatif terhadap penelitian ini adalah media SEJUK yang berorientasi pada kelompok yang terdiskriminasi seperti LGBT dalam masyarakat untuk mendapatkan hakhak LGBT.

Komunikasi massa menurut Bittner (Romli, 2016 : 1) adalah pesan yang dikomunikasikan melalui media massa pada sejumlah besar orang (massa communication is messeges communicated through a mass medium to a large number of people). Komunikasi harus menggunakan media massa, sehingga 
komunikasi tersebut disampaikan kepada khalayak ramai, jika tidak menggunakan media massa, maka komunikasi tersebut tidak termasuk komunikasi massa. Pesan dalam komunikasi massa dapat berupa fakta, peristiwa atau opini. Hubungan teori komunikasi massa terhadap penelitian ini adalah bahwa SEJUK menyampaikan informasi baik fakta, maupun opini melalui media massa kepada khalayak banyak, dengan upaya masyarakat dapat mengetahui informasi apa yang ditulis atau ditampilkan oleh media SEJUK.

Media massa memiliki kemajuan pesat seiring dengan perkembangan teknologi komunikasi, komunikasi massa tentu semakin canggih dan kompleks, serta memiliki kekuatan yang lebih dari massa-massa sebelumnya. Hal ini ditandai dengan munculnya media baru. Istilah "media baru" telah digunakan sejak tahun 1960-an dan telah mencakup seperangkat teknologi terapan yang semakin berkembang dan beragam. Hubungan teori media baru dengan penelitian ini adalah media SEJUK menampilkan informasi-informasinya melalui media sosial dan juga pada website SEJUK. Media sosial dan website merupakan sebuah media baru yang didukung dengan "internet", internet dapat menyampaikan berbagai macam media cetak, siaran film, dan rekaman dengan menggunakan sistem tanpa batas.

Ideologi adalah gagasan atau nilai pokok yang diusung oleh media massa melalui pesan yang disampaikan kepada khalayak. Hubungan teori ideologi media terhadap penelitian ini adalah dalam menampilkan artikelnya, ideologi media pada media SEJUK menampilkan pemberitaan yang kerap kali tidak dipublikasikan oleh media lain karena tertarik untuk mencari sebuah sensasi. SEJUK ingin khalayak dapat memahami bahwa komunitas LGBT lebih diperhatikan dan dapat dianggap sama oleh masyarakat meskipun terdapat perbedaan dari orientasi seksnya. Ideologi SEJUK mengacu kepada prinsipprinsip universal hak asasi manusia, prinsip-prinsip toleransi yang lebih umum dan juga prinsip-prinsip demokrasi. SEJUK mendorong dan menyebarkan sebagai bentuk sebuah perlindungan, penghormatan dan pemenuhan hak-hak kelompok minoritas tersebut.

Mengutamakan hak asasi manusia dan toleransi untuk keberagaman yang terjadi. SEJUK membuat kegiatan-kegiatan bersama dengan pihak media dan pihak gereja (keagamaan) untuk bekerja sama mencari suatu "win-win solution" agar mengurangi diskriminasi tersebut.

Fakta dan peristiwa adalah hasil konstruksi (Bungin, 2008 : 117). Realitas tercipta lewat konstruksi, sudut pandang tertentu dan tidak bersifat objektif karena realitas itu tercipta lewat konstruksi dan pandangan tertentu. Bahasa sebagai perangkat dasar, digunakan dalam menyampaikan isi media yang dimana isi tersebut adalah upaya hasil dari konstruksi sebuah realitas yang terjadi. Bahasa sendiri mampu menyampaikan maksud dari makna seperti yang dihasilkan oleh bahasa tentang realitas tersebut. Dengan demikian, media mempunyai kekuatan sendiri untuk mempengaruhi makna dari rekonstruksi sebuah realitas yang ada berdasarkan realitas media (Sobur, $2012: 88$ ).

Hubungan teori konstruksi realitas media terhadap penelitian ini adalah media SEJUK mengonseptualisasikan suatu keadaan dengan tetap memihak, menyuarakan terhadap kelompok-kelompok minoritas salah satunya LGBT yang memiliki orientasi gender dan seksualitas berbeda yang selama ini didiskriminasi oleh media mainstream dan pihak lain. Pemberitaan pada artikel SEJUK telah dibuktikan melalui pembelaan yang dilakukan kepada komunitas LGBT ini agar 
bisa mendapatkan hak-hak yang selama ini mereka butuhkan. Konstruksi realitas media ini terlihat jelas dari cara SEJUK sendiri dalam menyampaikan maksud yang dihasilkan oleh realitasnya. SEJUK melihat suatu situasi bahwa banyaknya pandangan atau persepsi diskriminasi, intoleransi, sikap maupun aksi masyarakat di Indonesia semakin meningkat. SEJUK ingin memberikan ruang atau suara yang lebih berimbang, setidaknya membuat publik mendengar adanya suara alternatif dari sekedar yang tidak toleran, sampai yang tidak menghargai.

\section{Simpulan}

Sebagai media alternatif bukan hal yang mudah untuk dapat dikenal dan mendapatkan khalayak serta bertahan di tengah arus media mainstream yang terus berusaha mencari popularitas dari caranya mempublikasikan berita. Media alternatif melakukan pemberitaan tidak untuk mendapatkan hasil keuntungan komersial, melainkan untuk menyuarakan kepada kaum minoritas, salah satunya adalah komunitas LGBT.

Media SEJUK membingkai bahwa LGBT layak untuk diberikan dukungan baik oleh kalangan gereja maupun media. SEJUK juga membingkai bahwa penyebab diskriminasi yang terjadi itu merupakan permasalahan dari media yang tidak mendukung dari segi pemberitaan yang dipublikasikan kepada khalayak. Dari segi diskriminasi yang dirasakan oleh komunitas LGBT itulah media SEJUK memaparkan ideologi atas tekanan dari pihak-pihak tersebut kepada komunitas LGBT.

Dalam pembingkaian artikel, SEJUK lebih menonjolkan keberpihakannya terhadap komunitas LGBT merupakan manusia yang biasa juga memiliki kesetaraan hak yang sama, memiliki hak asasi manusia, hak untuk hidup dengan nyaman dan aman di masyarakat maupun ditempat beribadah. Media SEJUK memberikan ruang bagi LGBT, memperlakukan hak LGBT sebagaimana orientasi seksual hetero lainnya.

\section{Ucapan Terima kasih}

Penulis mengucapkan terima kasih kepada pihak-pihak yang telah memberikan sumbang saran pengetahuannya, terutama kepada dosen pembimbing Ibu Septia Winduwati, S. Sos M.Si yang telah memberikan saran pendapat dalam penyelesaian skripsi dan penulisan jurnal ilmiah.

\section{Daftar Pustaka}

Adiputra, Wisnu Martha. (2012). Media Baru : Studi Teoritis Dan Telaah Dari Perspektif Politik dan Sosiokultural. Buku I. Yogyakarta: Fisipol UGM.

Alex, Sobur. (2012). Analisis Teks Media. Bandung : PT Remaja Rosdakarya.

Ardianto, Elvinaro, dkk. (2007). Komunikasi Massa Suatu Pengantar. Bandung : Simbosa Rekatama Media.

Biagi, Shirley. (2010). Media/Impact : Pengantar Media Massa. Jakarta : Salemba Humanika.

Eriyanto. (2002). Analisis Framing Konstruksi, Ideologi, dan Politik Media. Yogyakarta: LkiS.

Eriyanto (2011). Analisis Framing : Konstruksi, Ideologi, dan Politik Media. Yogyakarta: LkiS. 
Gunawan, Imam (2014). Metode Penelitian Kualitatif : Teori dan Praktik. Jakarta: PT Bumi Aksara.

McQuail, Denis. (2011). Teori Komunikasi Massa McQuail, Edisi 6 Buku 1. Jakarta: Salemba Humanika.

Moleong, Lexy J. (2010). Metodologi Penelitian Kuantitatif. Bandung : PT Remaja Rosdakarya.

Romli, Khomsarial. (2016). Komunikasi Massa. Jakarta:Grasindo. 